\title{
IMPERIALISMO, PETRÓLEO E O INTERVENCIONISMO OCIDENTAL: ANÁLISE DA GUERRA CIVIL NA LÍBIA (2011-2020)1
}

\author{
IMPERIALISM, OIL AND WESTERN INTERVENTIONISM: ANALYSIS OF \\ THE LIBYAN CIVIL WAR (2011 - 2020)
}

DOI: $10.5380 /$ cg.v10i1.74925

\author{
Ana Karolina Morais da Silva² \\ Beatriz dos Santos Abreu3
}

Issam Rabih Menem4

\begin{abstract}
Resumo
No presente artigo, buscamos analisar, a partir de uma perspectiva crítica, a invasão da OTAN à Líbia em 2011 e o conflito civil desencadeado a partir desta. $\mathrm{O}$ artigo está estruturado em três grandes capítulos. O primeiro tem como objetivo apresentar o conceito de Imperialismo a partir da teoria marxista. Em seguida, é elaborada uma revisão histórica de como o território líbio se insere no sistema internacional e na agenda das grandes potências ocidentais a partir da descoberta e da nacionalização do petróleo. Por fim, é desenvolvida uma análise de conjuntura do conflito político-militar que se desenrola naquele território a partir da intervenção da Organização do Tratado do Atlântico Norte. Parte-se da premissa de que o imperialismo ocidental se reconfigurou no século XXI, expondo sua faceta mais violenta e espoliadora, especialmente a partir das invasões do Afeganistão e do Iraque, em 2001 e em 2003, respectivamente. Ao longo das duas últimas décadas, países ricos em recursos energéticos governados por grupos políticos assumidamente antiocidentais têm sido alvo constante do intervencionismo ocidental. A acumulação via espoliação, estratégia do capital que foi intensificada desde a primeira crise do petróleo em 1973, surge como compensação pelos problemas crônicos de sobreacumulação que surgiram no âmbito da reprodução capitalista expandida. A Líbia, especialmente a partir da ascensão de Kadafi em 1969, esteve envolvida no epicentro da luta antiimperialista dos países produtores de petróleo e, no contexto da Primavera Árabe, sofreu uma intervenção da OTAN, justificada pelos princípios de defesa da democracia ocidental.
\end{abstract}

Palavras-Chave: Imperialismo; Petróleo; Intervencionismo; OTAN; Líbia.

\begin{abstract}
In this article, we seek to analyze, from a critical perspective, the NATO invasion of Libya in 2011 and the civil conflict unleashed from there. This article has three major chapters: the first one aims to present the concept of "Imperialism" based on a Marxist theory. Then, a historical review of how Libyan territory inserts itself in
\end{abstract}

\footnotetext{
${ }^{1}$ Este artigo está licenciado sob a Licença Creative Commons Attribution (CC BY 4.0), sendo permitido o compartilhamento com reconhecimento da autoria e publicação inicial nesta revista.

${ }^{2}$ Mestranda em Integração Contemporânea da América Latina (PPG-ICAL) da Universidade Federal da Integração Latino-Americana (UNILA). Pesquisadora associada do Núcleo de Estudos Estratégicos, Geopolítica e Integração Regional (NEEGI). E-mail: anakmorais96@gmail.com. ORCID: https://orcid.org/o000-0002-5627-9325.

3 Mestranda em Relações Internacionais (PPG-RI) da Universidade Federal da Integração Latino-Americana (UNILA). E-mail: abreubeat@gmail.com. ORCID: https://orcid.org/o0oo-0002-7280-4433.

4 Doutorando em Estudos Estratégicos Internacionais (PPG-EEI) da Universidade Federal do Rio Grande do Sul. Pesquisador do Núcleo de Estudos Estratégicos, Geopolítica e Integração Regional (NEEGI). E-mail: issam menem@hotmail.com. ORCID: https://orcid.org/o00o-0002-4636-8666.
} 
the international system and the agenda of major Western powers from the discovery and nationalization of oil is elaborated. Finally, a situational analysis of the political-military conflict that unfolds in that territory is developed from the intervention of the North Atlantic Treaty Organization. We start from the premise that Western imperialism was reconfigured in the 21st century, exposing its most violent and despoiling facet, especially after the invasions of Afghanistan and Iraq in 2001 and 2003, respectively. Over the past two decades, countries rich in energy resources governed by openly anti-Western political groups have been a constant target of Western interventionism. Accumulation via spoliation, a strategy of capital that was intensified since the first oil crisis in 1973, appears as compensation for the chronic problems of overaccumulation that arose in the context of expanded capitalist reproduction. Libya, especially since the rise of Gadhafi in 1969, was involved in the epicenter of the anti-imperialist struggle of oil-producing countries and, in the context of the Arab Spring, it suffered NATO intervention, justified by the principles of defense of Western democracy.

Keywords: Imperialism; Oil; Interventionism; NATO; Libya.

\section{INTRODUÇÃO}

Neste artigo, buscamos desenvolver uma análise histórico-documental da intervenção militar da OTAN à Líbia em 2011, partindo da hipótese de que esta é o resultado do imperialismo ocidental no Oriente Médio, com o objetivo de espoliação e pilhagem de recursos como o petróleo. A análise está focada na guerra que se inicia na Líbia em 2011, após a intervenção militar das potências ocidentais. Inicialmente, é feito um levantamento teórico-conceitual acerca do fenômeno do imperialismo na contemporaneidade, com especial relevância ao papel do controle sobre os recursos naturais estratégicos como mecanismo de garantia do status quo vigente na distribuição do poder e das riquezas no sistema internacional.

Em seguida, é feita uma análise histórica do governo de Muammar Kadafi, em que buscamos definir quais eram as políticas internas e externas do Estado líbio a partir de 1969, e quais foram as estratégias que garantiram o controle estatal sobre as reservas de petróleo nesse período. O objetivo é esmiuçar os antecedentes da intervenção da OTAN, definindo os motivos que fizeram de Kadafi um inimigo do imperialismo ocidental no continente africano. Após isto, buscamos discutir a afirmação da hegemonia estadunidense a partir de 1990 baseada em sua política intervencionista, somada à uma retórica dicotômica entre Ocidente e Oriente que se fortaleceu após o 11 de Setembro, fundamentando e legitimando a intervenção e a troca de regime em muitos países do Oriente Médio e da África.

Na quarta e última seção, explora-se a invasão na Líbia que ocorre sob um discurso baseado na defesa da democracia e dos direitos humanos a partir do Conselho de Segurança da ONU e das deliberações acerca da Responsabilidade de Proteger. Em seguida, é realizada uma historiografia política do cenário líbio pós-intervenção, realçando a criação das primeiras instituições políticas pósintervenção e as rupturas que ocorreram entre elas. À vista da grande fragmentação política na Líbia, atores internos buscam por alianças externas como forma de financiar militarmente e legitimar politicamente suas ações internas. 


\section{IMPERIALISMO E PETRÓLEO: A APROPRIAÇÃO DO CAPITAL SOBRE RECURSOS NATURAIS}

O conceito de imperialismo, cuja aplicação por autores marxistas remonta ao princípio do século XX, retoma força no início do século XXI e passa a integrar o debate das Relações Internacionais com maior centralidade. A importância da categoria se deve à relevância do debate crítico sobre o papel do Estado no capitalismo, especialmente a partir da intensificação da internacionalização das relações de produção (OSÓRIO, 2018).

No marco do imperialismo tradicional e/ou clássico, cujo nome de maior destaque foi Lênin, o pensador revolucionário foi categórico ao definir o imperialismo como uma fase do capitalismo, ao contrário da maior parte dos pensadores do início do século XX, que definiam o fenômeno de outras formas ${ }^{5}$ O autor considera que o imperialismo haveria surgido como um desenvolvimento do capitalismo, e prioriza em sua análise o papel do capital financeiro e dos monopólios dentro deste. Em outras palavras, o imperialismo seria uma continuação direta do capitalismo, o qual havia atingido um elevado grau de desenvolvimento (LÊNIN, 2005).

Assim, o imperialismo estaria constituído pela combinação de determinados elementos, como o monopolismo, a predominância do capital financeiro (associação do capital bancário com o capital industrial), a exportação de capitais e a divisão do controle da economia mundial entre associações capitalistas internacionais e países capitalistas desenvolvidos. Segundo Lênin, o imperialismo seria uma etapa final do capitalismo por precarizar ainda mais as condições de vida dos povos oprimidos e, com isso, acelerar a própria deterioração desse modo de produção (LÊNIN, 2005).

Sobre a guerra e a conflitividade intraimperialista, Lênin afirmava que "faz parte da própria essência do imperialismo a rivalidade de várias grandes potências nas suas aspirações por hegemonia, isto é, a apoderar-se de territórios não tanto diretamente para si, como para enfraquecer o adversário e minar a sua hegemonia" (LÊNIN, 2005, p. 92).

Por outro lado, Kautsky postulava que a guerra era um meio para o desenvolvimento do capitalismo, ao mesmo tempo que seria um obstáculo para ele, pois prejudicava os preços de mercado e os lucros capitalistas. Em sua opinião, a guerra intraimperialista iria perder o sentido no longo prazo, pois seria prejudicial aos capitalistas. Entretanto, as proposições do pensador tchecoaustríaco não foram confirmadas na conjuntura do entre guerras, entre 1919 e 1939 (KAUTSKY, 2012).

Se o debate clássico do imperialismo se centrava especialmente sobre o capital financeiro, o monopólio e as causas e consequências da guerra imperialista, o debate contemporâneo tem profunda relação com o contexto internacional do pós-Guerra Fria, marcado pela intensificação da instabilidade e da violência na semiperiferia e na periferia do sistema, uma vez que as grandes

5 Como, por exemplo, John Hobson, Rudolf Hilferding, Rosa Luxemburgo e Karl Kautsky. 
potências têm o poder de decidir sobre quando e onde empregar o uso da força, a qual é geralmente direcionada para áreas marginais, desde o ponto de vista geopolítico, das relações internacionais (OSÓRIO, 2018). Segundo Osório, isto ocorre porque:

a frágil interação do centro metropolitano é baseada na cooperação e no conflito, vinculada à permanente concorrência por controle de mercados, áreas de investimento e fontes de matérias-primas, bem como a manutenção da ordem mundial. Assim, os conflitos interimperialistas de eras passadas já não se deflagram, como desde o pós-Segunda Guerra, tendo em vista a concentração da violência militar em uma superpotência. Contra ela e sem ela mais nenhuma guerra convencional é travada (OSÓRIO, 2018, p. 131).

Com o fim da Guerra Fria, multiplicaram-se as intervenções militares, operações desestabilizadoras e bloqueios econômicos contra regimes que resistem à ordem mundial imposta pelo capital, assim como deflagraram-se muitos conflitos e tensões por áreas de influência. Ainda assim, segundo Rolando Astarita, a razão de ser dessa violência sistemática já não é a pilhagem direta ou a imposição da empresa colonial. Dessa forma, o autor defende que o imperialismo pode ser compreendido como um produto das tendências do capitalismo globalizado à centralização e concentração de capitais, o controle sobre o trabalho, a comercialização de todos os valores de uso, a mudança permanente das forças produtivas e a consequente competição que dela decorre, o que gera uma crise de acumulação pela queda nas taxas de lucro. Como resposta a essas tendências, os Estados mais poderosos levam a cabo operações (militares ou não) para assegurar a exploração do trabalho, especialmente em um contexto em que a luta de classes e as imposições dos mercados intensificam as tensões sociais em todo o mundo (ASTARITA, 2006).

David Harvey, em "O novo imperialismo", busca analisar a atual condição do capitalismo, descrevendo a passagem da hegemonia britânica para a hegemonia estadunidense e como a segunda passava por um momento de reafirmação e endurecimento no início do século XXI. Seguindo essa lógica, o autor afirma que as invasões do Afeganistão e do Iraque marcaram o início de um "novo imperialismo" estadunidense (HARVEY, 2004).

O império estadunidense, em seus primórdios, vivia um estado de negação, em que não assumia seu poder como imperial e, portanto, o desempenhava de forma mais branda. O debate acerca do imperialismo estadunidense remonta ao final da Primeira Guerra Mundial e, até o final do século XX, não havia consenso sobre as características desse imperialismo e sua origem. Entretanto, mesmo quando ainda se discutia a natureza do poder imperial estadunidense, a potência norteamericana já empregava seu discurso de exportação da democracia para a aplicação de inúmeros golpes de Estado na América Latina, entre 1950 e 1970, e, anos mais tarde, o mesmo discurso serviria para a tentativa de justificação das invasões do Afeganistão, em 2001, e do Iraque, em 2003 (HARVEY, 2004).

Marx, em "A chamada acumulação primitiva”, capítulo XXIV de sua obra "O Capital”, descreve processos coloniais, neocoloniais e imperiais de apropriação violenta de ativos, inclusive de 
recursos naturais, como meios radicais de acumulação primitiva via espoliação (MARX, 1987) e, desde a Segunda Guerra Mundial, qualquer plano de controlar a economia global perpassa o controle geopolítico do Oriente Médio, como região que concentra as maiores reservas energéticas do mundo (HARVEY, 2004).

Segundo Harvey, as características da acumulação primitiva que Marx menciona permanecem fortemente presentes na geografia histórica do capitalismo até os nossos dias. Ademais, foram criados também mecanismos inteiramente novos de acumulação por espoliação, e alguns dos mecanismos da acumulação primitiva que Marx enfatizou foram aprimorados para desempenhar hoje um papel mais relevante do que o desempenhado no passado (HARVEY, 2004).

A acumulação por espoliação se tornou cada vez mais acentuada a partir de 1973, em parte como compensação pelos problemas crônicos de superacumulação que surgiram no âmbito da reprodução expandida. Para que isso ocorresse, além da financeirização e da liberalização comercial, criou-se uma abordagem radicalmente distinta da maneira como o poder do Estado, sempre um grande agente da acumulação por espoliação, devia se desenvolver: a teoria neoliberal e sua política de privatização simbolizaram grande parcela do tom geral dessa transição. O veículo primário da acumulação por espoliação tem sido a abertura forçada de mercados em todo o mundo mediante pressões institucionais exercidas por meio do FMI e da OMC, apoiados pelo poder dos Estados Unidos (e, em menor grau, pela Europa) de negar acesso ao seu próprio mercado interno aos países que se recusam a desmantelar suas proteções. A ascensão de uma política internacionalista de neoliberalismo e privatização está vinculada a surtos periódicos de desvalorização predatória de ativos em distintas partes do globo, e este é o cerne da natureza da prática imperialista contemporânea (HARVEY, 2004).

\section{A LÍBIA DE KADAFI E O INTERVENCIONISMO OCIDENTAL}

As reservas de petróleo da Líbia foram descobertas no ano de 1957. Desde então, o país possui uma das maiores reservas de petróleo do mundo, possuindo a maior capacidade petrolífera do continente africano. Por essa razão, diversas empresas multinacionais do ramo petrolífero passaram a adentrar o país em busca de oportunidades de empreendimentos desde a segunda metade do século XX.

A partir da sua independência, em 1952, a Líbia era governada pela monarquia Idriss. Sob esse governo, o controle do petróleo líbio era monopolizado pelas "Sete Irmãs", sete transnacionais que controlaram o ramo petrolífero até 1960 e, atualmente, após aquisições e fusões, são apenas quatro empresas, duas estadunidenses (ExxonMobil e ChevronTexaco) e duas britânicas (Shell e $\mathrm{BP})$. 
Na década de 1960, a Líbia não possuía tecnologia o suficiente para a exploração dos próprios recursos, o que facilitou a entrada das empresas transnacionais em seu território e, consequentemente, a renda petrolífera gerada na Líbia não ficava retida no país, mas era convertida em remessas de lucro que eram enviadas diretamente para os países-sede das Sete Irmãs: Estados Unidos e Reino Unido (OLIVEIRA, 2015).

Contudo, em 1969, ascende ao poder, através de um golpe militar, um grupo político de inspiração socialista, anticolonial e defensor do nacionalismo árabe, liderado por Muammar Kadafi. A tomada do poder ocorreu por uma articulação política dentro das bases militares do país por um pequeno grupo que se chamava Oficiais Livres, composto por 70 militares revolucionários que, liderados por Kadafi, tomaram o poder e destituíram a monarquia. No período da ascensão política de Kadafi, também estava em emergência o nacionalismo árabe, movimento político liderado pelo egípcio Gamal Nasser e que se espalhou por todo o Oriente Médio, influenciando também o pensamento político de Kadafi.

A partir desse momento, inicia-se um processo revolucionário na Líbia, por meio do qual é estruturado o Estado de Jamahiriya, ou "Estado de Massas", baseado na teoria da participação política da sociedade civil na composição do Estado, combinando o socialismo e o islã, com princípios de igualdade fundados em valores de igualitarismo político e econômico. A partir da instauração desse novo regime político, realiza-se a reforma agrária, o padrão de vida do povo líbio passou a ser gradativamente elevado e houve uma redução da mortalidade infantil.

O socialismo defendido por Kadafi possuía características próprias voltadas à cultura árabe e à prática do Alcorão. De acordo com Simons:

A primeira fase da revolução líbia, apelidada de nasserista, envolveu a transformação do país dessa sociedade pré-capitalista em um sistema estatal, que envolvia um componente capitalista predominante. A segunda fase, por sua vez, foi marcada pela aplicação do "Estado das Massas", em que Kadafi procurou consagrar um conceito de sistema político e econômico coletivo, de forma que nenhuma parte da população fosse marginalizada (SIMONS, 1996).

Em 1973, a Líbia adentra um processo de Revolução Cultural, sendo criados cerca de dois mil Comitês Populares espalhados por todo o território líbio, operando como espaços políticos responsáveis por fomentar a participação política do povo no planejamento e processos decisórios do Estado. Os Comitês Populares em conjunto formavam o Comitê Nacional do Povo, submetido a eleições periódicas que ocorriam de quatro em quatro anos (GIORDANI; BORGES, 2017).

Em 1976, Kadafi reúne suas aspirações políticas em conjunto com a nova estrutura de organização do Estado líbio por meio da publicação do Livro Verde. Na obra, faz uma crítica ao modelo de democracia representativa liberal e ocidental e, como alternativa a esse modelo político, propõe uma Democracia Direta, que seria alcançada a partir do fomento de espaços de discussões e deliberações políticas promovidas a partir da base social. Na teoria, o objetivo da Democracia Direta é empoderar e politizar os setores populares às suas próprias demandas e aspirações políticas. 
Ademais, vale ressaltar que, a partir do Livro Verde, Kadafi também nos traz ideais relacionados ao pan-arabismo e ao socialismo árabe. Para Kadafi:

A atividade econômica na nova sociedade socialista é a atividade produtiva para a satisfação das necessidades materiais. Não é uma atividade estéril ou com o objetivo do lucro depois de satisfeitas as necessidades materiais. Tal é impossível segundo as regras do novo socialismo (KADAFI, 1976. p. 61).

Internamente, o novo governo redistribuiu a renda petroleira em investimentos sociais ${ }^{6}$, como moradia e educação, estatizando as funções de importação, exportação e distribuição (LUBASZEWSKI, 2016). Ademais, as políticas de Kadafi estiveram voltadas ao fortalecimento da soberania energética da Líbia (GIORDANI; BORGES, 2017). Sob o regime de Kadafi, mais de 50\% dos bancos estrangeiros que atuavam na Líbia foram nacionalizados, assim como as redes de distribuição de petróleo (HAJJAR, 1980).

O governo de Kadafi não se enquadrava nos padrões democráticos ocidentais, pois buscava construir um modelo de democracia direta, diferente da democracia representativa. Contudo é importante ressaltar que tal processo político apresenta limites e contradições. Estes podem ser exemplificados quando observamos as perseguições e a alta repressão policial a manifestantes e demais alas de oposição ao governo. Críticos apontam que o poder era distribuído informalmente entre as pessoas próximas a Kadafi e que os Comitês Populares poderiam servir de instrumento para controle político das massas, controlando também o setor petrolífero, a polícia, a política externa e o exército (LUBASZEWSKI, 2016).

A nível internacional, a década de 1970 foi marcada pela primeira crise de produção do petróleo que, entre outros motivos, ocorreu pela articulação da Organização dos Países Exportadores de Petróleo (OPEP), na qual a Líbia já atuava como membro ativo, em função do aumento do preço da commodity diante do poder de monopólio que as Sete Irmãs mantinham. A crise do petróleo de 1973 paralisou o sistema produtivo petrolífero em diversos países ocidentais e, consequentemente, desestabilizou os sistemas econômico e financeiro internacionais. Contudo é a partir da crise que os países organizados na OPEP demonstraram o impacto que suas políticas coordenadas poderiam causar a nível global.

Nesse contexto, a nova política externa do Estado líbio desempenhou um papel fundamental. Kadafi “foi o primeiro líder de um país árabe a lançar uma política de redução da produção para defender a gestão das reservas petrolíferas e pressionar os preços em alta” (COSTA SILVA, 2005, p.

\footnotetext{
${ }^{6} \mathrm{Na}$ década de 1990, a Líbia se tornou o país com maior renda per capita do continente africano. "A Líbia possuía o maior Produto Nacional Bruto (PNB) e o mais alto Índice de Desenvolvimento Humano (IDH) do continente" (LUNDIN, 2011) e ainda: "O orçamento para a educação era de cerca de 30\% e em 1998 chegou a $38,2 \%$. A taxa de alfabetização é de aproximadamente $82 \%$. Com uma população de 6,5 milhões de habitantes, em torno da metade abaixo dos 15 anos, a Líbia criou doze universidades, com 200 mil estudantes no total, e 84 institutos técnicos e vocacionais, com cerca de 70 mil estudantes no total, todos, então, financiados pelo Estado. A situação habitacional era também saudada pelos relatórios do PNUD como exemplar" (LUNDIN, 2011, p. 4).
} 
8). A Líbia passava a ser cada vez mais vista como um inimigo político das potências ocidentais, pois além de se tornar um Estado autossuficiente economicamente após as descobertas de reservas de petróleo, possuía uma crescente influência tanto no Oriente Médio quanto no continente africano (COSTA SILVA, 2005).

No nível externo, a ascensão de Kadafi representa uma transformação na posição política adotada pelo Estado líbio, que, a partir de então, passa a se opor aos interesses das potências ocidentais, voltando suas políticas para o continente africano (GIORDANI; BORGES, 2017), empregando um discurso abertamente nacionalista e anticolonial.

A partir da década de 1990, com a dissolução da URSS, a política internacional adentrou um processo de afirmação da hegemonia estadunidense que se materializou tanto pela via econômica, com a imposição de reformas estruturais e liberalização comercial a grande parte do mundo (na América Latina, por exemplo, com o Consenso de Washington), quanto pela via militar, por meio de inúmeras intervenções em países de inexpressiva capacidade bélica.

Contudo é sob a liderança e influência de Kadafi que é organizada a União Africana, em 1999, e a Nova Parceria para o Desenvolvimento da África, em 2002. Ambas as organizações, baseadas nos ideais desenvolvimentistas e independentistas, reafirmaram as deliberações políticas dos africanos diante das problemáticas do continente, ressaltando o posicionamento africano sobre as próprias problemáticas regionais e dificultando, em certa medida, a intervenção estrangeira direta dentro de tais negociações. Dessa forma, observamos que a política externa da Líbia tinha como prioridade o continente africano desde o ponto de vista estratégico, buscando se constituir enquanto uma potência política a nível regional (FERNANDES; DIALLO; GARCIA, 2012).

É importante mencionar também o apoio de Kadafi ao Congresso Nacional Africano (CNA), tal iniciativa era destinada a aumentar a autonomia dos governos africanos, fato que constituiu um motivo importante para a demonização da Líbia, tida como alvo futuro de mudança de regime pelas políticas estadunidenses (LITTLEJOHN, 2017).

Ao terminar a década de 1990, a distribuição geopolítica das novas bases militares dos Estados Unidos pelo mundo demonstrava a superioridade do país norte-americano no âmbito militar a nível global, controlando uma fortíssima infraestrutura que sustenta sua preponderância geopolítica em relação às demais potências. Os Estados Unidos contavam "com mais de 700 bases ao redor do mundo, com acordos de ‘apoio militar recíproco' com cerca de 130 países, com o controle soberano de todos os oceanos e com a capacidade de intervenção quase instantânea em qualquer ponto do espaço aéreo mundial" (FIORI, 2007, p. 88).

Nesse contexto, Harvey (2004) postula que a acumulação via espoliação se tornou central para o capitalismo global e, não por acaso, a hegemonia e o domínio dos Estados Unidos estão em crise: as causas dessa oscilação estão no emprego desequilibrado do capital financeiro como meio de afirmar a sua hegemonia. A opção do governo Bush pelo unilateralismo, pela coerção em vez do 
consentimento e pelo uso irrestrito do poder militar, indica uma abordagem de alto risco à sustentação do domínio estadunidense mediante o controle militar dos recursos energéticos.

Essa nova postura internacional mais agressiva por parte dos Estados Unidos possui relação com o que passava no plano interno do país no início dos anos 2000, pois, com a ascensão do neoconservadorismo, o combate ao terrorismo e a guerra com o Iraque serviram como elementos aglutinadores para a sociedade estadunidense ao redor de um inimigo externo comum, que havia sido perdido desde a dissolução da URSS, o que permitia ao Estado norte-americano acumular mais poder (HARVEY, 2004).

Após 2001, a estratégia de segurança nacional dos EUA lançou o mundo em uma retórica de guerra que opõe Ocidente a Oriente e tensiona conflitos em toda a periferia do sistema interestatal, ao passo que as intervenções da grande potência passaram a ser cada vez menos aceitas pela comunidade internacional, o que se intensificou após a invasão da OTAN à Líbia, e, a partir de 2013, na Guerra na Síria.

A presença de importantes reservas de petróleo e gás no Oriente Médio tem sido um dos principais motivos para a ingerência externa das potências ocidentais na região. O Oriente Médio, com suas importantes reservas de petróleo - cerca de 70\% do total mundial (KERR OLIVEIRA, 2012, p. 188) - há décadas representa um importante pilar da estratégia geopolítica de dominação estadunidense. O petróleo, principal recurso energético no século XX e também no XXI, possui relevância estratégica e econômica vital para os Estados Unidos. Por esse motivo, o controle das principais reservas de petróleo do mundo é essencial para a manutenção do poderio estadunidense e sua posição no sistema internacional (FUSER, 2013; AMIN, 2004).

Nas últimas décadas do século XX e no início do século XXI, os EUA desenvolveram uma estratégia baseada na dominação imperialista, direta ou indireta, de territórios que contam com alto excedente de recursos energéticos. Durante a Guerra Fria, os Estados Unidos mantiveram sua influência sobre o Oriente Médio por meio de aliados regionais que atuavam como representantes dos seus interesses na região - Arábia Saudita e Irã, após o golpe perpetrado em 1953 - e, entre 1940 e 1967, suas empresas passaram a possuir 60\% de controle sobre as reservas de petróleo da região (HARVEY, 2004, p. 26). Após a crise de 1973 e a Revolução Iraniana de 1978-1979, a estratégia estadunidense para a região foi modificada e o país passou a fomentar cada vez mais conflitos entre os países da região, intensificando a belicosidade de sua estratégia de dominação (idem, p. 27) e ampliando sua presença militar no Oriente Médio para securitizar seu acesso e de seus aliados ao petróleo (KERR OLIVEIRA, 2012, p. 195).

A Guerra Irã-Iraque (1980-1988) foi um marco dessa nova estratégia e a Guerra do Golfo (1990-1991) efetivamente permitiu que os EUA aumentassem sua presença militar no Oriente Médio, ao mesmo tempo que armavam, sem grandes impedimentos, os seus aliados na região (HARVEY, 2004, p. 27). Ao lado do Afeganistão e do Iraque, a intervenção na Líbia em 2011 representou outro exemplo dessa estratégia estadunidense. O "Grande Oriente Médio", como 
definido pelas palavras de Bush, em 2004, na reunião do G-8 realizada em Sea Islands, EUA, seria "um novo espaço de intervenção geopolítica, que iria do Marrocos até o Paquistão" (FIORI, 2011). Dessa forma, observamos que, para a política externa estadunidense, o "Grande Oriente Médio" deveria ser reconfigurado por meio da instabilidade política generalizada e da derrubada de governos, com vistas a impedir o surgimento de potências regionais não alinhadas aos interesses ocidentais, exatamente a posição internacional a qual a Líbia aspirava ocupar.

A intervenção militar na Líbia, apesar de ter seu início em 2011, já era planejada pelo pentágono desde 2003. Wesley Clark, ex-comandante militar da OTAN, em seu livro "Winning Modern Wars: Iraq, Terrorism And The American Empire”, de 2003, publica uma lista de países que deveriam ser alvo de intervenções dos Estados Unidos a fim de garantir o controle sobre recursos energéticos e rotas comerciais de hidrocarbonetos. Na lista, estão países como Iraque, Síria, Líbia, Líbano, Somália, Sudão e Irã. Assim, tais intervenções ocorreriam com o objetivo de estabilizar o preço do petróleo, a manutenção da influência ocidental sobre o Oriente Médio e assegurar garantias comerciais para as empresas multinacionais nesses territórios (CLARK, 2003).

\section{A INVASÃO À LÍBIA EM 2011 E O CONFLITO CIVIL SUBSEQUENTE}

As agitações políticas em território líbio se iniciaram em 2011 com o advento da Primavera Árabe, um movimento baseado em manifestações visando a mudança de regimes em diversos países do Grande Oriente Médio. As manifestações que começaram na Tunísia logo se espalharam pela maior parte do mundo árabe, chegando ao Egito, Iêmen, Arábia Saudita, Bahrein e outros. Em 2011, a oposição ao governo de Kadafi organizou uma série de manifestações e protestos que tinham como principal objetivo a troca de regime e a retirada de Kadafi do poder. As manifestações se iniciaram na capital Trípoli e foram reprimidas pelo governo, que respondeu violentamente aos protestos. No embate entre forças da oposição e do governo, muitas pessoas morreram e, como resposta a essas mortes, foi justificada a intervenção militar da OTAN na Líbia. Após o rompante das manifestações, o Conselho de Segurança da ONU condenou a atuação do governo líbio e aprovou a Resolução 1973, um documento que ampara intervenções militares a partir do princípio da Responsabilidade de Proteger, sob os fundamentos de democracia e da defesa dos direitos humanos (PAUTASSO; AZEREDO, 2011).

A noção de Responsabilidade de Proteger foi cunhado pela primeira vez no ano de 2001, no relatório intitulado "Responsibility to Protect", redigido pela International Commission on Intervention State Sovereignty (ICISS). Tal comissão, criada pelo governo canadense, surgiu em 2000 como uma tentativa de responder às demandas sobre como a comunidade internacional deveria reagir diante de violações sistemáticas de direitos humanos. Sob essa noção, a soberania de

um Estado está associada a uma gama de responsabilidades e, caso essas responsabilidades 
deixassem de ser cumpridas, o princípio da não intervenção deveria ser precedido pelo princípio da responsabilidade internacional de proteger. Dessa forma, o conceito de soberania, historicamente definido como o exercício da autoridade plena sobre determinado território e sua população, seria ressignificado e interpretado como uma responsabilidade mínima perante um território e sua população, sobre os quais é exercido controle político. Quando tal responsabilidade não é efetivada, ou seja, quando não há garantia de níveis mínimos de direitos humanos para a população, a soberania estatal pode ser questionada (MELLO, 2013).

Contudo a aplicação prática da Responsabilidade de Proteger tende a atender aos interesses dos Estados mais poderosos do sistema internacional, sendo norteada por seis elementos chave: (i) a necessidade de afirmação da autoridade das Nações Unidas, em especial do Conselho de Segurança, quando há um país condenado dentro do sistema internacional; (ii) a determinação de momentos que uma intervenção pode ser justificada, quando há grande número de perda de vidas e quando ocorre uma "limpeza étnica" por meios violentos, como massacre, terrorismo e estupro; (iii) as intervenções ocorridas sob o amparo da Responsabilidade de Proteger devem evitar mortes e maiores sofrimentos humanos, e ocorrerem de acordo com os interesses da população protegida; (iv) as ações da Responsabilidade de Proteger ocorrem quando outros mecanismos de pressão internacional já tiverem falhado, como pressões diplomáticas, embargos econômicos e de produtos bélicos, fechamento de embaixadas etc; (v) nas ações, os recursos humanos e bélicos devem ser mínimos para que se evite o aprofundamento da violência e da perda de vidas; e (vi) as intervenções ocorridas pela Responsabilidade de Proteger são bem sucedidas quando acabam com o problema em questão sem gerar mais conflitos e mortes (PAUTASSO; AZEREDO, 2011).

A partir da intervenção militar realizada pela OTAN na Líbia, o número de mortos no conflito aumentou de maneira drástica, e a missão, que tinha na teoria o objetivo de diminuir o conflito, potencializou e aprofundou a guerra na Líbia. Além de proporcionar mais violência, a intervenção gerou a troca de regime na Líbia, a possibilidade de fragmentação do território e a morte de seu líder político em praça pública, cujas imagens foram televisionadas e transmitidas em todo o mundo (ZAMUDIO, 2015).

Depois da intervenção, notamos uma crescente instabilidade política na Líbia e a destruição de grande parte da infraestrutura do país. Para Zamudio (2015, p. 6, tradução nossa7), "após a agressão imperialista, a Líbia ficou destruída, sem infraestrutura, sem estradas, sem escolas, nem hospitais, já que até estes foram bombardeado", de forma que os seis eixos da Responsabilidade de Proteger não foram cumpridos pelas ações militares desenvolvidas.

Os bombardeios da OTAN procuraram preservar a infraestrutura de petróleo e gás do país, apesar de destruírem toda a infraestrutura básica para assegurar os serviços de saúde, educação e transporte para a população líbia. Assim que foram revogadas as sanções econômicas impostas pela

7 Texto original: "luego de la agresión imperialista, Libia quedó destruida, sin infraestructura ni vial, ni escuelas, ni hospitales, ya que hasta éstos fueron bombardeados". 
Resolução 1973, após a morte de Kadafi, já em 2012, o país havia retomado sua produção petrolífera. Entretanto, a partir de 2013, os conflitos políticos internos levaram a outra queda da produção (BRASIL, 2017).

À época da invasão, Wallerstein criticou a ação militar na Líbia, afirmando ser um erro desde o ponto de vista estratégico, mas também do ponto de vista humanitário. $\mathrm{O}$ autor ressaltou que a postura do presidente Obama, em 2011, deixava claro que, caso a intervenção servisse aos interesses estratégicos estadunidenses, ela seria realizada de qualquer maneira, independentemente dos seus custos humanos (WALLERSTEIN, 2011). Ademais, Samir Amin também teceu duras críticas à invasão da OTAN à Líbia em 2011:

Desde o seu início, o "movimento" da Líbia tomou a forma de uma revolta armada em combate contra o exército, e não de uma vaga manifestação civil. E logo em seguida essa revolta chamou a NATO (Organização do Tratado do Atlântico Norte) em sua ajuda. Assim foi dada, às potências imperialistas, a oportunidade para uma intervenção militar. O seu objetivo seguramente não era "a protecção dos civis" nem a "democracia", mas sim o controle sobre os campos petrolíferos, os recursos aquíferos subterrâneos e a aquisição de uma importante base militar no país (AMIN, 2011, s/p).

Portanto, como analistas de relações internacionais apontaram logo após a invasão e como os desdobramentos do conflito corroboram (principalmente pela destruição de toda a infraestrutura não petroleira), é possível afirmar que a Responsabilidade de Proteger, embora tenha servido como pano de fundo jurídico para a intervenção militar em território líbio, nesse caso, não correspondeu aos objetivos que deveria buscar consolidar, pelo menos em sua concepção teórica. Na Líbia, os princípios norteadores da Resolução 1973 foram solapados pela preocupação central de garantir que a infraestrutura petrolífera seguisse operante após a destituição de Kadafi e, portanto, a intervenção da OTAN promoveu, fundamentalmente, um cenário de caos e conflito políticos que se arrastam até os dias atuais.

Em meio à investida contra Muammar Kadafi, as principais figuras do movimento de oposição ao regime estabeleceram o Conselho Nacional de Transição (CNT), sob liderança de Mustafa Abdul Jalil. O conselho anunciado em março de 2011 intitulou-se o "único governo legítimo" da nova "República Líbia". Rapidamente, o CNT ganhou respaldo internacional e representou o país nas mais importantes organizações internacionais, como a Organização das Nações Unidas e a Liga Árabe (LACHER, 2020, p. 21).

Diversos setores da sociedade e facções formavam o CNT, desde importantes líderes desertores das Forças Armadas Líbias até políticos e intelectuais exilados. Pelo grande número de representantes e importantes figuras que formavam o CNT, eclodiram conflitos internos entre os diferentes setores que participavam do conselho, tornando a estrutura organizacional da instituição nada transparente e impraticável. A morte de Kadafi em outubro do mesmo ano (2011) borbulhou a ganância pelo poder e os diferentes interesses que existiam na organização; desertores formaram 
seus respectivos movimentos políticos com seus braços armados e conexões internacionais. Assim, a cidade de Trípoli se transformou em um campo de batalha, frustrando todas as tentativas de estabilização da região pelo CNT (LACHER, 2020, p. 22-23).

Com a Líbia totalmente "livre" do regime de Kadafi, o CNT é dissolvido e é criado o Congresso Geral Nacional (CGN), composto por 200 legisladores eleitos na primeira eleição realizada após 60 anos. Apesar das eleições apresentarem certo sucesso com 60\% de participação (GLOBO, 2012), setores da sociedade líbia e facções armadas não reconheceram seu resultado. O descontentamento desses grupos fragilizou o poder e a legitimidade do CGN. Tentativas de golpe foram registradas contra o então eleito primeiro-ministro Ali Zidan, que, no ano de 2014, exilou-se na Alemanha. Desde então, a Líbia é um território heterogêneo com diferentes facções lutando pelo poder.

Em fevereiro daquele ano (2014), um ex-general do Exército Líbio e uma das principais figuras do extinto CNT, Khalifa Haftar, realiza uma transmissão em rede nacional suspendendo arbitrariamente o Conselho Geral Nacional e o polêmico artigo oitavo. Porém seu anúncio não obteve efeitos empíricos. A partir do momento daquela transmissão, o general iniciou um significativo trabalho de recrutamento, principalmente de militares do Exército Líbio, de civis marginalizados, assim como de fundamentalistas religiosos. Com aos militares, Khalifa Haftar conquistou uma significativa quantia de material bélico, como blindados e aviões militares. Esses artefatos foram cruciais para a tomada da cidade de Benghazi. As vitoriosas campanhas de Haftar contra grupos terroristas na região de Benghazi apresentou ao Oriente Médio um líder promissor para a árdua missão de estabilização e unificação da Líbia. Assim, países como a Arábia Saudita, Egito e Emirados Árabes Unidos forneceram não só apoio político ao grupo de Haftar, mas importante apoio bélico. Nesse momento, a Líbia tem dois grandes governos representativos, o Governo de Tobruk, apoiado pelo exército de Haftar, e o Governo de Trípoli, sob a gestão do CGN (ERDAĞ, 2017, p. 35-36).

A profunda crise socioeconômica e a falta de um poder central oportunizaram a emergência de grupos terroristas pelo país, dentre eles o Daesh/ISIS. O grupo terrorista (ISIS) infiltrou-se na Líbia sem muita resistência e, em certo momento, dominou importantes regiões, como a cidade mediterrânea de Derna. Regionalmente, o fortalecimento do ISIS na Líbia motivou grande alarde à comunidade europeia, pela proximidade do continente e do vizinho Egito, que compartilha uma longa fronteira com a Líbia. Não obstante o apoio militar ao exército de Haftar, o Egito lançou ofensivas militares aéreas contra postos do ISIS em território líbio (ERDAĞ, 2017, p. 51-52). O conflito interno líbio constrange toda a região do sub-complexo do Magrebe.

$\mathrm{O}$ ano de 2015 se inicia com o território líbio totalmente fragmentado politicamente e militarmente. Dentre os principais grupos de poder, o Exército de Haftar representando o Governo de Tobruk; as forças do Governo de Trípoli; Tribos Tubu e Tuaregue ao sul e em regiões interioranas e fronteiriças; e grupos terroristas espalhados pelo país, principalmente em regiões com pouca densidade humana. 
Após esforços por parte das Nações Unidas para um acordo entre os atores mais relevantes do conflito, em dezembro de 2015, é assinada a iniciativa do Governo do Acordo Nacional (GAN), única autoridade reconhecida como legítima pela ONU, assim como pelo Conselho de Segurança na Líbia, apesar de instituição não ser totalmente reconhecida tanto pelo Congresso Geral Nacional (CGN) como pela Câmara dos Representantes da Líbia (Governo de Tobruk). Desde a criação e o reconhecimento do GAN, o CGN perdeu influência no cenário político e muitos de seus membros se retiraram da organização (THE NATIONAL, 2016).

Em contrapartida, o Khalifa Haftar, apoiador da Câmara dos Representantes da Líbia, recebe o apelido de "Senhor da Guerra" pelas sucessivas e vitoriosas campanhas militares pelo leste e sul da Líbia. Em 2019, o Exército Nacional da Líbia, liderado por Haftar, domina grande parte do país, incluindo diversos campos de petróleo, e marcha em sentido à capital, Trípoli (THE ECONOMIST, 2019). Apesar de não ter apoio de instituições internacionais ocidentais, o General Haftar tem ao seu lado potências regionais como o Egito, a Arábia Saudita, os Emirados Árabes Unidos, tal como apoio (não oficial) de potências internacionais como Rússia e França.

Além do auxílio logístico e bombardeios aéreos, o vizinho Egito fornece dados de inteligência e financia mercenários, principalmente da tribo Awlad Ali. A Arábia Saudita e os Emirados Árabes Unidos forneceram às tropas de Haftar importantes veículos blindados, carros de combate, modernos veículos aéreos não tripulados e sistemas de defesa antiaéreo. A Rússia, além do apoio político, fornece, de modo não oficial, milhares de mercenários do Wagner Group (PMC Wagner). Já a França, além de ser o maior aliado político de Haftar em instituições internacionais, fornece dados de inteligência (CLASH REPORT, 2020). Na imagem 1 é possível observar as alianças estratégicas dos atores mais relevantes do conflito líbio.

Por outro lado, o Governo de Acordo Nacional tem politicamente ao seu lado instituições internacionais de grande prestígio, como a ONU, a União Europeia e a Otan, sendo reconhecido como o único representante executivo da Líbia. Militarmente, a Turquia é publicamente, o maior aliado do governo de Trípoli. A Turquia não só apoia formalmente o Governo de Acordo Nacional, como interveio diretamente na Líbia, onde obteve vitórias contra os liderados pelo General Haftar, utilizando parte importante de seu aparato militar (ASIA TIMES, 2020).

A presença turca na Líbia é percebida de diversas formas. Milhares de mercenários financiados por Ancara foram transferidos da Síria para a Líbia; navios e submarinos turcos se fazem presentes na costa de Trípoli, além de soldados turcos com experiência na Síria, os quais treinam militares do GAN a utilizarem drones (Veículo aéreo não tripulado) militares de última geração. A intervenção militar de Recep Tayyip Erdoğan na Líbia mostra-se uma luz de esperança para o fraco Governo de Trípoli de um dia exercer sua governabilidade por todo o território líbio (TRT WORLD, 2020). 


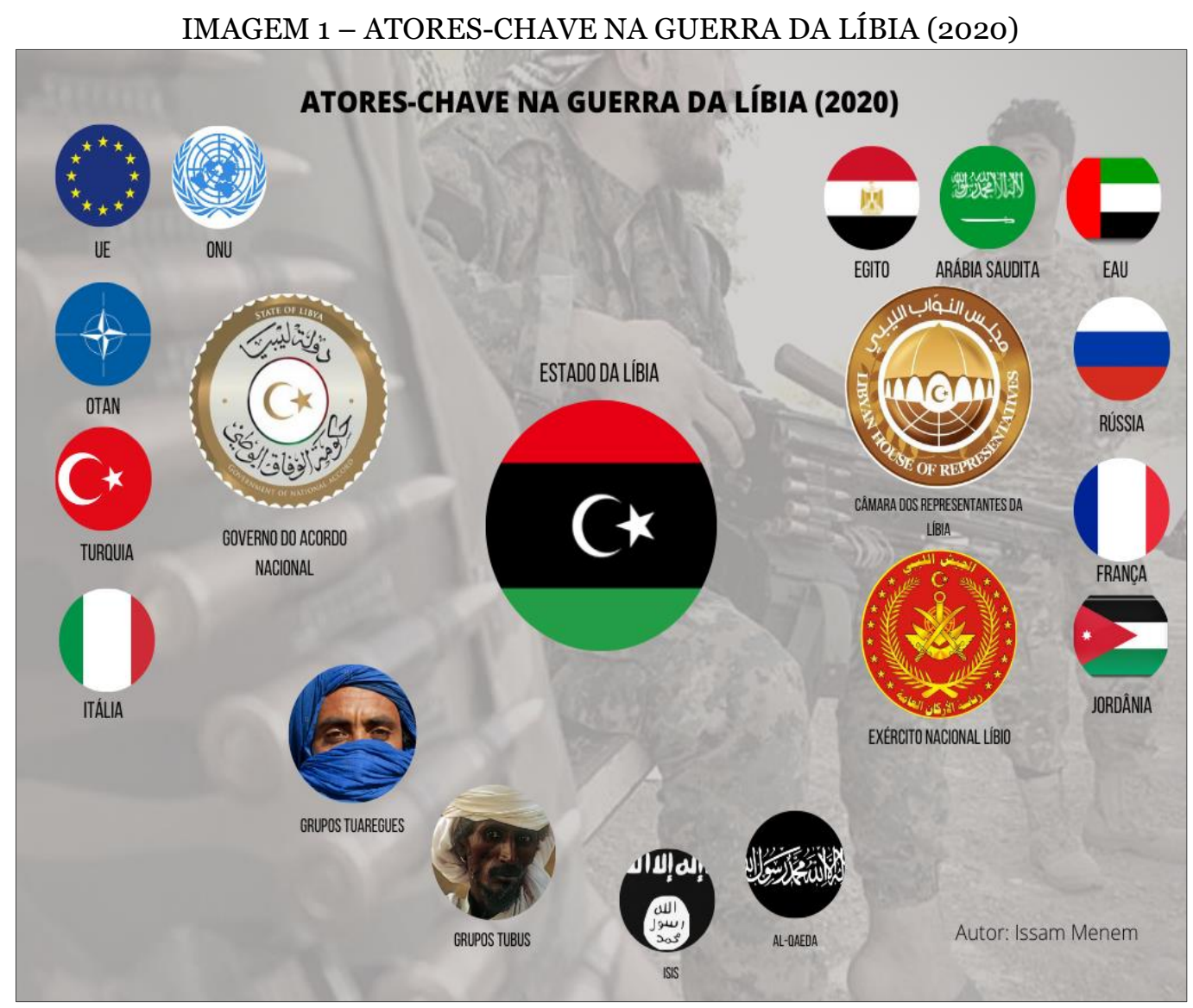

Fonte: imagem elaborada pelos autores.

O esforço político e militar turco na Líbia está baseado em um acordo com o Governo de Acordo Nacional (Trípoli), que delineou suas respectivas Zonas Econômicas Exclusivas (ZEE), de tal maneira que divide o Mar Mediterrâneo em duas seções entre a Turquia e a Líbia, obrigando que países mediterrâneos negociem com a Turquia qualquer gasoduto que tenha como destino a Europa. A conduta do governo turco é norteada pela doutrina "Pátria Azul". Essa doutrina prevê o domínio do Egeu, de importante parte do Mediterrâneo e do Mar Negro (ASIA TIMES, 2020).

O cenário líbio se mostra conturbado e incerto. As alianças militares alteraram-se diversas vezes desde o começo do conflito e são muito dinâmicas, visto a grande quantidade de atores e os diferentes interesses. A resistência de Bashar Al-Assad na Síria fez com que muitas potências regionais e internacionais voltassem os olhos para a Líbia nos últimos anos, elevando o nível tecnológico do conflito que até então não apresenta qualquer possibilidade de desfecho.

\section{CONSIDERAÇÕES FINAIS}

A guerra na Líbia oferece um exemplo recente da estratégia de dominação imperialista desenvolvida pelas potências ocidentais, especialmente os Estados Unidos, desde o final da Guerra Fria. Tal estratégia baseia-se fundamentalmente em aproveitar-se de momentos de instabilidade 
política (em alguns casos, gerar tal instabilidade) para promover mudanças de regime em países com considerável excedente energético e cujos governos não estejam plenamente alinhados aos interesses econômicos ocidentais.

No caso líbio, as manifestações populares que, segundo Samir Amin, já surgiram sob forma de revolta armada contra o governo, haviam causado pouco mais de mil mortes no momento em que foi autorizada a intervenção militar ocidental. Após a intervenção, o número de mortos no conflito, que se arrasta desde 2011 (e que contou com momentos de esfriamento e de escalada oscilando entre si), já não pode ser calculado, mas estima-se que, até outubro de 2011, quando a invasão da OTAN finalizou a missão de assassinar Kadafi, o número de mortos era de 25 mil, além de quatro mil desaparecidos.

A Líbia, Estado cuja política interna e externa esteve voltada durante mais de 40 anos para a construção de um polo de poder regional, hoje encontra-se mergulhada em um caos político, social e econômico do qual nem sequer as potências ocidentais envolvidas na intervenção militar usufruem mais. Embora os primeiros meses após a morte de Kadafi tenham significado uma vitória política para o Estados Unidos, Reino Unido e França, que passaram a obter privilégios da produção petrolífera do país africano, o conflito subsequente instaurou um cenário de instabilidade que ameaça até mesmo a permanência do Estado líbio de forma unitária. Assim, o caso líbio é importante para repensar o modelo de intervenção que vem sendo aplicado pelos países ocidentais, seus limites e, mais ainda, suas motivações imperialistas e os impactos danosos que têm sobre a vida humana.

*Artigo recebido em 01 de julho de 2020, aprovado em 15 de janeiro de 2021.

\section{REFERÊNCIAS}

AMIN, S. U. S. Imperialism, Europe and the Middle East. Monthly Review, vol. 56, no 6, nov. 2004. Disponível em: <https://monthlyreview.org/2004/11/o1/u-s-imperialism-europe-and-themiddle-east/>. Acesso em: 31 jan. 2021.

AMIN, S. A Líbia pode desintegrar-se como a Somália. Pambazuka News. Tradução do Passa Palavra, set. 2011. Disponível em: <https://passapalavra.info/2011/o9/46204/>. Acesso em: 04 de dez. 2019.

ASIA TIMES. Turkey's 'Blue Homeland' doctrine takes shape in Libya. 2020. Disponível em: <https://asiatimes.com/2020/o6/turkeys-blue-homeland-doctrine-takes-shape-in-libya/>. Acesso em: 31 jan. 2021.

ASTARITA, R. Valor, mercado mundial y globalización. Buenos Aires: Tuprop, 2006. 
BRASIL, B. B. C. Líbia: um estudo da intervenção internacional de 2011 e de seus aspectos jurídicos e políticos. Dissertação de Mestrado. Instituto de Relações Internacionais. Universidade de São Paulo, 2017.

CLARK, W. Winning Modern Wars: Iraq, Terrorism And The American Empire. Jackson: Public Affairs, 2003.

CLASH REPORT. The Foreign Actors of the Libyan Civil War. 2020. Disponível em:<https://twitter.com/clashreport/status/1237425912523755521>. Acesso em: 31 jan. 2021.

COSTA SILVA, A. A Luta pelo Petróleo. Relações Internacionais, n. 6, p. 5-18. jun. 2005. Disponível em: <http://www.ipri.pt/index.php/pt/publicacoes/revista-r-i/arquivo-de-revista-ri/79-relacoes-internacionais-n-6>. Acesso em: 31 jan. 2021.

ERDAĞ, Ramazan. Libya in the Arab Spring: from revolution to insecurity. New York: Springer, 2017.

FERNANDES, L. N; DIALLO, M. A; GARCIA, M. L. A. Conflito na Líbia: uma análise crítica do intervencionismo ocidental pelo poder e recursos energéticos em nome da defesa da democracia. Pambazuka News: voices for freedom and justice, 03 mar. 2011. Disponível em: <https://www.pambazuka.org/pt/governance/conflito-na-líbia-uma-análise-crítica-dointervencionismo-ocidental-pelo-poder-e-recursos $>$. Acesso em: 31 jan. 2021.

FIORI, J. L. A Líbia, a Otan e o Grande Médio Oriente. Valor, o1 agosto de 2011. Disponível em: <http://www.valor.com.br/opiniao/993648/libia-otan-e-o-grande-medio- oriente>. Acesso em: 31 jan. 2021.

FIORI, J. L. A nova geopolítica das nações e o lugar da Rússia, China, Índia, Brasil e África do Sul. Revista Oikos, Rio de Janeiro, v. 6, n. 2, p. 77-106, 2007.

FUSER, I. Energia e Relações Internacionais. São Paulo: Editora Saraiva, 2013.

GIORDANI, F; BORGES, G. A Revolução Cultural e Popular na Líbia de 1973. Revista Perspectiva, v. 10, n. 18, p. 100-115, 2017.

GLOBO. Eleições na Líbia têm protestos e lágrimas de alegria. 2012. Disponível em:<http://g1.globo.com/revolta-arabe/noticia/2012/o7/eleicoes-na-libia-tem-protestos-elagrimas-de-alegria-x.html>. Acesso em: 31 jan. 2021.

HAJJAR, Sami G. The Jamahiriya Experiment in Libya: Qadhafi and Rousseau. The Journal of Modern African Studies, Vol. 18, No. 2, pp. 181-200. Cambridge: Cambridge University Press, 1980. Disponível em: <www.jstor.org/stable/160277?seq=1>. Acesso em: 31 jan. 2021.

HARVEY, D. O Novo Imperialismo. São Paulo: Edições Loyola, 2004.

KADAFI, M. O Livro Verde. Edição: Ridendo Castigat Mores. Versão para eBook. Campinas: Biblioteca Digital da PUC, 1976. Disponível em: <http://bibliotecadigital.puccampinas.edu.br/services/e-books/Muammar\%20Al\%20Qathafi-1.pdf>. Acesso em: 31 jan. 2021.

KAUTSKY, K. Ultra-Imperialismo. In: FREITAS, G. B. Tradução e análise dos artigos de Karl Kautsky acerca do imperialismo e seus desdobramentos em relação à economia e sociedade contemporânea e o Brasil. Texto para Monografia do curso de Ciências Econômicas da Faculdade de Ciências e Letras de Araraquara (FCLAr) da Universidade Estadual Paulista (UNESP), 2012. 
KERR OLIVEIRA, L. Energia como Recurso de Poder na Política Internacional: os desafios da Geopolítica do Petróleo e o papel do Centro de Decisão Energética. Tese de Doutorado em Ciência Política. Universidade Federal do Rio Grande do Sul, 2012.

LACHER, Wolfram. Libya's Fragmentation: Structure and Process in Violent Conflict. London: Bloomsbury Publishing, 2020.

LÊNIN, V. I. O imperialismo, fase superior do capitalismo. 3. ed. São Paulo: Centauro, 2005.

LITTLEJOHN. G. Libya's Plunge: Gaddafi, Western Intervention and Imperialism. Review of African Political Economy, 2017. Disponível em: <http://roape.net/2017/o3/27/libyas-plungegaddafi-western-intervention-imperialism/> . Acesso em: 31 jan. 2021.

LUBASZEWSKI, N. P. Líbia: importância Estratégica e Inserção Regional. (1969-2015). Trabalho de conclusão de curso em Relações Internacionais. UFRGS, Porto Alegre, 2016.

LUNDIN, I. B. A intervenção Militar na Líbia. Tensões Mundiais, v. 7. n. 13, p. 193-209, 2011.

MARX, K. O Capital: Crítica da Economia Política. Livro Primeiro, O processo de produção do capital. Volume I, 11 a Edição. Tradução de Reginaldo Sant'anna. São Paulo: Editora Bertrand Brasil, 1987.

MELlo, J. A. A Soberania e a Responsabilidade de Proteger. Trabalho de Conclusão de Curso. Bacharelado em Ciências Jurídicas e Sociais, Faculdade de Direito da Pontifícia Universidade Católica do Rio Grande do Sul. Porto Alegre, 2013.

OLIVEIRA, A. P. Nos porões da Crise da Energia. Série Livros Geográficos. Florianópolis: UFSC /CFH / GCN, 2015.

OSÓRIO, L. F. Imperialismo, Estado e Relações Internacionais. São Paulo: Ideias \& Letras, 2018.

PAUTASSO, D; AZEREDO, R. L. Expansão do Poder dos Estados Unidos: o caso da Líbia. Tensões Mundiais, v. 7, n. 13, p. 169-192, 2011.

SIMONS, Geoff. Libya: The Struggle for Survival. 2. Ed. Londres: Palgrave Macmillan, 1996.

THE NATIONAL. One year on, UN-backed government fails to unite Libya. 2016. Disponível em: <https://www.thenational.ae/world/one-year-on-un-backed-government-fails-tounite-libya-1.197890>. Acesso em: 31 jan. 2021.

THE ECONOMIST. Khalifa Haftar, Libya's strongest warlord, makes a push for Tripoli. 2016. Disponível em: <https://www.economist.com/middle-east-and-africa/2019/04/05/khalifahaftar-libyas-strongest-warlord-makes-a-push-for-tripoli>. Acesso em: 31 jan. 2021.

TRT WORLD. Why did Turkey sign a maritime deal with Libya?. 2019. Disponível em:<https://www.trtworld.com/turkey/why-did-turkey-sign-a-maritime-deal-with-libya-32064>. Acesso em: 31 jan. 2021.

WALLERSTEIN, I. A grande manobra diversionista na Líbia. Tradução: Katarina Peixoto. Carta Maior, 2 abr. 2011. Disponível em: <https://www.cartamaior.com.br/?/Editoria/Internacional/Agrande-manobra-diversionista-na-Libia\%250D\%250A/6/16810 >. Acesso em: 31 jan. 2021.

ZAMUDIO, C. Éxodos dantescos y guerras imperialistas: Crímenes del capitalismo. Kavilando, v. 7, n. 2, p. 193-200, 2015. 